\title{
Los conflictos de 1624 y 1808 en la Nueva España
}

Verónica Zárate Toscano

Instituto Mora, México, D. F.

Estudio de dos movimientos de gran impacto en el México colonial. Los motines ocurridos en la capital del virreinato novohispano en 1624 y 1808 tienen dos marcos políticos distintos pero se analizan aqui a la luz de acciones contra el Estado, en una perspectiva comparativa; el marco histórico,los actores, los medios y los resultados de esas acciones cooperan a un mejor conocimiento de ambos movimientos coloniales, separados por casi dos siglos de distancia.

\section{Preliminar}

Las transformaciones políticas de la Corona española entre 1624 y 1808 provocaron cambios sustanciales en el sistema político virreinal de Nueva España. La Casa de Austria tuvo como política general el "patrimonialismo corporativo", a diferencia de los Borbones, que establecieron el "centralismo absolutista". Por consiguiente, los motines ocurridos en la ciudad de México en 1624 y 1808 tienen dos marcos políticos distintos; de aquí se deriva la importancia de conocerlos.

Los analizaremos a la luz de lo que se ha definido como coup d'etat. Pensamos que ambos movimientos políticos pueden ser entendidos a partir de esta categoría ya que reúnen los elementos indispensables que los caracterizan. Entendemos por golpe de estado la apropiación, por parte de un grupo, de los órganos y las atribuciones del poder político, mediante una acción sorpresiva con cierto margen de violencia pero sin que esta sea la nota permanente. ${ }^{1}$

Al comparar los golpes de estado de 1624 y 1808 se hace evidente que aún con algunas similitudes, guardan enormes diferencias ya que cada uno respondió a circunstancias históricas determinadas. Pero también salta a la vista que el sistema político colonial no fue plenamente estático sino que tuvo que afrontar graves problemas internos y externos que pusieron a prueba su capacidad. El motín de 1624 se puede considerar como una

1 La definición de golpe de estado ha sufrido ciertas modificaciones a lo largo de la historia, como se puede ver en Norberto Bobbio y Nicola Matteucci: Diccionario de Política, Mexico, 1981, vol. 1 , pags. $745-749$. 
advertencia que no alcanzó a tener consecuencias desastrosas e inmediatas para la Corona española. Pero el golpe de 1808 fue más que una advertencia, pues la conjunción de múltiples factores externos e internos ayudó a que se produjera un rompimiento irreversible con España.

\section{Fuentes}

Para el estudio de estos conflictos, existe una abundante documentación; sin embargo, no siempre es de fácil acceso y parte de ella se conoce sólo por referencias. En ambos casos, consumada la caída del gobernante, se justificó o explicó, por parte de instituciones y particulares, su participación en los conflictos, lo que dejó valiosos testimonios, lógicamente muy partidistas, pero importantes para el entendimiento de esos fenómenos. Seguramente existieron también múltiples versiones orales, aderezadas conforme se extendían en el campo del rumor. Algunas de ellas han sido recogidas en documentos y dan diversos puntos de vista que fueron hechos circular con toda intención por los involucrados.

A pesar de todo, falta aclarar algunos aspectos en torno al caso de 1624; el golpe de 1808, por otro lado, ha recibido mucha atención sobre todo por su relación con la lucha independentista.

En 1624 no sólo los actores sino los que consideraron que tenían algo que decir al respecto, particularmente la Audiencia, el virrey y el arzobispo, elaboraron o mandaron escribir memoriales que hicieron llegar a España y que en algunos casos circularon impresos, ${ }^{2}$ enviaron sus delegados o se presentaron directamente ante la Corona, como lo hizo el arzobispo. Además de las fuentes de primera mano, existen diversas e interesantes interpretaciones vertidas en algunas obras de Thomas Gage, Andrés Cavo, José María Luis Mora, Hubert Howe Bancroft, Vicente Riva Palacio, Rosa Feijoo, Jonathan Israel, Richard Boyer y Enrique Florescano. ${ }^{3}$

2 Algunos autores hablan de seis diferentes folletos sobre el tema. Sin embargo, sólo hemos tenido acceso a los documentos enlistados a continuación. Lewis Hanke, en su obra Los virreyes españoles en América durante el gobierno de la casa de Austria, Madrid, 1977, tomo III (275), publicó dos informes de Gelves, uno sobre el estado en que halló "la Nueva España y relación de lo sucedido en el tiempo que la gobernó y del tumulto y lo demás hasta que volvió a España", y otro preparado en Madrid en 1628, así como la "Sentencia del Consejo sobre el Marqués de Gelves" en su juicio de residencia. Igualmente conocemos un impreso elaborado por Cristóbal Ruiz de Cabrera: Algunos singulares y extraordinarios sucesos del gobierno de don Diego Pimentel, marqués de Gelves.

3 Gage, Thomas: Viajes en la Nueva España, La Habana, 1980. Cavo, Andrés: Historia de México, México, 1949. Mora, José María Luis: Méjico y sus revoluciones, Paris, Librería de Rosa, 1836. Bancroft, Hubert Howe: History of Mexico, en History of the Pacific States, San Francisco, 
En 1808 la Audiencia preparó largos y circunstanciados documentos explicativos. ${ }^{4}$ Además, 180 de los golpistas nombraron un portavoz, Marcos Berazaluce, que tomó como misión dar a conocer en España lo que "verdaderamente había pasado", el cual falleció en el camino. ${ }^{5}$ Pero, como dice Lucas Alamán, "si la muerte privaba a los españoles de los agentes que mandaba a sostener su causa en la corte, el mismo Arzobispo los proveyó del más activo y eficaz que pudieran desear en la persona de don Juan López Cancelada". ${ }^{6}$ El depuesto virrey tuvo que defenderse ante el tribunal que lo juzgaba por infidente, el que le llevaba la Residencia y los ataques públicos y publicados. ${ }^{7}$ Además, para el estudio de esa época se cuenta ya con la valiosa ayuda que proporcionan los periódicos de la capital del virreinato, la Gaceta y el Diario de México, que contienen en sus páginas

A.L. Bancroft Pub., 1883, vol. VI, (México III, 1600-1803). Riva Palacio, Vicente: El virreinato, t. II de México a través de los siglos, México, 1976. Feijoo, Rosa: "El tumulto de 1624", en Historia Mexicana, vol. XIV, n. 1 [53], México, julio-septiembre de 1964, págs. 42-70. Israel, Jonathan I.: Raza, clases sociales y vida política en el México colonial 1610-1670, México, 1980. Boyer, Richard E.: "Absolutism versus Corporatism in New Spain: the Administration of the Marquis of Gelves, 1621-1624", The International History Review, IV, 4, november 1982, pags. 475-503. Florescano, Enrique y Rodrigo Martínez: Historia gráfica de México. Epoca colonial, México, 1988.

4 La vastísima documentación de las instituciones y los juicios se custodia en el Archivo Histórico Nacional de Madrid (AHN), Consejos, 21081 y 21082, en el Archivo General de Indias (AGI), México, passim y en el Archivo General de la Nación (AGN), Historia passim.

5 AGI, Mexico, 1321.

6 Alamán, Lucas: Historia de Méjico, Méjico, 1972, t. I, pág. 199.

7 Particularmente interesante es la polémica generada por los folletos publicados por Juan López Cancelada: La verdad sabida y buena fe guardada. Origen de la espantosa revolución de Nueva España comenzada en 15 de setiembre de 1810. Defensa de su fidelidad, Cádiz, Imprenta de Manuel Santiago de Quintana, 1811, y Conducta del excelentísimo señor don José de Iturrigaray durante su gobierno en Nueva España. Se contesta a la vindicación que publicó don Facundo Lizarza, Cádiz, Imprenta del Estado Mayor General, 1812. La defensa del virrey la realizó José Ignacio Beye Cisneros, firmada como Discurso que publica don Facundo Lizarza vindicando al excelentísimo señor don José Iturrigaray de las falsas imputaciones de un cuaderno titulado por ironía Verdad Sabida y buena fe guardada, Cádiz, Oficina de Nicolás Gómez Requena, 1811. En el mismo sentido se publicó El excelentísimo señor don José de Iturrigaray, virrey que fue de Nueva España vindicado en forma legal contra las falsas imputaciones de infidencia propuestas por el Acuerdo de México y apoyadas por don Juan López Cancelada en sus dos manifiestos, Cádiz, Imprenta Tormentaria, 1812. Tampoco hay que olvidar que fray Servando Teresa de Mier escribió defendiendo a Iturrigaray su Historia de la Revolución de Nueva España, antiguo Anáhuac, o verdadero origen y causas de ella con la relación de sus progresos hasta el presente año de 1813, México, 1981. Por último hay que mencionar el Verdadero origen, carácter, causas, resortes, fines y progresos de la revolución de Nueva España, y defensa de los europeos en general residentes en ella y especialmente de los autores de la aprehensión y destitución del virrey d. José de Iturrigaray en la noche del 15 de setiembre de 1808, contra los falsos calumniadores que los infaman, y atribuyen al indicado suceso, a opresión, agresiones y ofensas de su parte contra los americanos, la desastrosa revolución que ha asolado este reino, atribuida a Juan Martín Juanmartiñena y publicada en México, Juan Bautista Arizpe, 1820. Dichos textos han sido analizados en mi tesis de maestría: Juan López Cancelada: vida y obra, México, UNAM, 1986, 214 págs. 
la crónica "fresca" de los acontecimientos. ${ }^{8}$ Como estudios monográficos sobre el período de Iturrigaray existen las obras de Lafuente Ferrari, Lawrence Black y Francisco Santiago Cruz. ${ }^{9}$ Además, se le trata como antecedente en prácticamente todas las obras que se ocupan de la guerra de Independencia.

\section{Antecedentes}

Es necesario hacer una breve descripción de los antecedentes que culminaron con la caída de los virreyes novohispanos, para luego analizar algunos de los factores que nos parecen esenciales en dichos golpes de estado.

En 1624 gobernaba la Nueva España Diego Carrillo de Mendoza y Pimentel, marqués de Gelves y conde de Priego. A sus 67 años, contaba con una amplia experiencia al servicio de la Corona por el desempeño de puestos públicos y militares. Su envío a la Nueva España respondió a la necesidad de aplicar una política reformista que en España era encabezada por el conde-duque de Olivares, primer ministro de Felipe IV.

El objetivo de la corte española era reducir el déficit presupuestario, para lo cual se pensó en crear un sistema bancario apoyado en una reforma fiscal. Gelves traía la consigna de allegar recursos a la monarquía, eliminando la evasión fiscal, castigando la corrupción y modificando el sistema administrativo. Eran tan apremiantes los cambios por él introducidos, que Jonathan Israel ha señalado: "Si se conseguía reformar la administración americana y disciplinar más efectivamente a sus funcionarios, la Corona esperaba, con toda razón, recibir una enorme recompensa". ${ }^{10}$

Por todo ello, no resulta extraño que Gelves, cuando llegó a la Nueva España, comenzara a luchar contra los vicios, el crimen, el despilfarro y la corrupción. Adoptó una política benevolente con las clases más desvalidas, afectando con ello intereses particulares que reaccionaron en su contra y provocaron su caída.

8 Zárate Toscano, Verónica: La prensa mexicana y el gobierno del virrey Iturrigaray, Tesis de licenciatura en Historia, Mexico, UNAM, 1982, 162 págs.

9 Lafuente Ferrari, Enrique: El virrey Iturrigaray y los orígenes de la Independencia de Méjico, Madrid, 1941. Black, Lawrence L.: Conflict among the elites: the overthrow of viceroy Iturrigaray, Mexico, 1808, Tulane University, Ph. D., 1980, 346 págs. y Santiago Cruz, Francisco: El virrey Iturrigaray. Historia de una conspiración, México, 1965.

10 Israel, J.: Raza, clases sociales..., pág. 140. 
En 1808, el derrocamiento tuvo características distintas. La silla virreinal estaba ocupada por José de Iturrigaray y Aróstegui, teniente general de los Reales Ejércitos, quien había dedicado buena parte de sus 66 años al servicio militar. El puesto lo había obtenido gracias a la política española de seleccionar entre los militares a los virreyes que pudieran hacer frente a la amenaza bélica latente, y a su amistad con el primer ministro Manuel Godoy. Durante su gestión se aplicó uno de los últimos recursos de la Corona en el marco de las llamadas reformas borbónicas: la Consolidación de Vales Reales. Iturrigaray, con el fin de congraciarse con algunos sectores, llevó a cabo varias obras para el mejoramiento del virreinato y las condiciones de vida de la población, todo ello sin descuidar la pulcritud de su imagen y el culto a su personalidad.

La autoridad virreinal no fue ajena a la crisis política española del verano de 1808. Napoleón se apropió del monarca español y su territorio. Esta situación generó en Nueva España el rompimiento del orden gubernamental, desarrollándose un clima de confusión y conflicto que aparentemente culminó con la caída de Iturrigaray.

\section{Los Actores}

El estudio de Rosa Feijoo acerca del golpe de 1624 contradice la versión de la corriente historiográfica que le ha dado a este un carácter de "motín de granos". Ella ha dicho y comprobado "que si en el tumulto hubo alguna causa económica, no fue ésta la más inmediata ni la más importante". ${ }^{11}$ Esta conclusión nos llevó a investigar, siguiendo nuestro plan de análisis, a los sectores que participaron en la organización del golpe de estado.

En primer lugar, las diferencias políticas se iniciaron entre Melchor Pérez de Varaez y el virrey marqués de Gelves. Hasta donde los documentos nos lo permiten, podemos afirmar que el motivo de la disputa fue el de frenar la especulación en el abasto de grano y carne. Considerando que Varaez era el causante de estas irregularidades, el virrey entabló un juicio en su contra. Esta acción generó que otros sectores salieran en su defensa, principalmente el presidente de la Audiencia, Pedro de Vergara Gabiria, y el arzobispo de México, Juan Pérez de la Serna. Es importante señalar que

11 Feijoo, R.:’El tumulto...”, pág. 45. 
la alianza entre Varaez, Gabiria y De la Serna durante todo el conflicto fue muy sólida, aunque es difícil precisar los términos de su pacto, tarea que podría interesar a otros historiadores.

Con la intervención del arzobispo, el conflicto adquirió el carácter de fricción entre autoridad civil y religiosa. Esta situación sirvió como detonante, generando con ello la participación y radicalización de otros sectores.

El virrey se apoyó en la Audiencia para contrarrestar la fuerza de sus enemigos, pero con el paso del tiempo su posición se debilitó debido al encarcelamiento a que sometió a algunos de sus miembros, entre ellos al propio Gabiria.

La labor de agitación por ciertos grupos religiosos, dio como resultado un enfrentamiento violento. "La plebe" participó en la defensa de los intereses del arzobispo. Adelantando conclusiones, podemos afirmar que la autoridad religiosa tenía en ese momento un mayor poder político que el propio virrey, que representaba a la máxima autoridad terrenal, mientras el arzobispo era el símbolo que encarnaba el poder divino.

La Audiencia, ante la amenaza de la plebe, decidió asumir las facultades y atribuciones del virrey y comenzó a jugar abiertamente el papel de líder del golpe de estado, es decir, monopolizó todas las funciones y sometió a los órganos políticos a su autoridad imponiendo un nuevo orden social.

Cabe resaltar, igualmente, la participación del marqués del Valle como mediador del conflicto, aunque su intervención claramente se inclinó a favor de los adversarios del virrey. El Cabildo y las fuerzas armadas fueron fieles observadoras de los acontecimientos, manteniendo una posición de "neutralidad-complicidad" durante el evento.

No podemos dejar de lado la intervención de la plebe, quien jugó un papel muy importante en la caída del virrey, pero es necesario decir que actuó motivada por ciertas circunstancias y no por voluntad propia, es decir que participó como el "coro" mientras que los actores principales fueron otros.

Finalmente debemos tomar en consideración el papel que jugaron los comerciantes. El Consulado tomó el bando del arzobispo por distintas razones. Su oposición a Gelves estaba fincada en la política mercantil que éste había tratado de implantar. Algunos de los miembros del tribunal aparecían muy relacionados con ciertos oficiales afectados por la campaña contra la corrupción y Louisa Hoberman ha identificado a Juan Francisco Vértiz 
como fiador de Varaez. ${ }^{12}$ Una vez depuesto el virrey, la Audiencia presionó al Consulado para que apoyara su decisión de asumir el gobierno. ${ }^{13}$

En el golpe de 1808 podemos identificar la participación de otros sectores sociales y órganos de gobierno. La opinión generalizada es que en su desarrollo se evidenció abiertamente el antagonismo entre criollos y peninsulares, o hablando en términos institucionales, entre el Ayuntamiento y la Audiencia.

Las diferencias políticas se hicieron palpables desde el momento en que el Ayuntamiento se apresuró a manifestar al virrey su posición respecto a la ausencia de monarca legítimo en España, presionándolo para que declarara su plan a seguir y buscando influenciarlo o manipularlo para que apoyara sus proposiciones de buscar la autonomía y convocar juntas de gobierno locales.

La Audiencia, por su parte, se mantuvo inicialmente a la expectativa haciendo que sus acciones dependieran de los pasos que adoptaran el Cabildo y el virrey. Paulatinamente, su postura se fue radicalizando mediante la consolidación de algunas alianzas que le permitieran actuar en defensa de los intereses de España, o más claramente, de los suyos propios.

El grupo de comerciantes españoles gozaba de un poder económico y un prestigio social considerables. Probablemente esto fue lo que motivó que la Audiencia acudiera a esta institución, buscando quien pudiera hacer abiertamente lo que ella no se atrevía. Los intereses consulares se habían visto afectados por algunas de las medidas del virrey, lo que justificaba su resentimiento hacia el mismo y las acciones que llevarán a cabo contra Iturrigaray.

Es un hecho real que para que un golpe de estado tenga éxito, es necesario que no sea un sector aislado el que lo lleve a cabo, sino que éste logre establecer una serie de alianzas. Una de las que más nos llama la atención en el conflicto de 1808 es la pasividad con que actuaron las fuerzas armadas. El ejército representaba ya en esta época un poder considerable y en su fortalecimiento y evolución había jugado un papel importante el virrey Iturrigaray. De ahí que fuera indispensable evitar que se dieran las condi-

12 Hoberman, Louisa Schell: "Merchants in Seventeenth-Century Mexico City: A Preliminary Portrait", The Hispanic American Historical Review, v. 57, n. 3, págs. 479-503, Durham, 1977, pág. 486.

13 AGN, Archivo Histórico de Hacienda, caja 213, legajo 11, fols. 241-246v. En septiembre de 1624 la Audiencia remitió un papel al Consulado pidiéndole que definiera su posición. Aparentemente y tras una seria deliberación, el Tribunal le contestó que obedecería las órdenes de la Audiencia como si vinieran del rey. 
ciones necesarias para que las tropas apoyaran a su comandante en caso que éste intentara cualquier movimiento.

La Iglesia en su conjunto no jugó un papel determinante en este conflicto. Algunos de sus representantes manifestaron sus puntos de vista en las juntas de autoridades. Los conspiradores trataron de atraer a su partido al arzobispo Francisco Xavier Lizana y Beaumont pero éste se negó a tomar parte y simplemente sancionó el cambio de gobernante mediante su presencia en el nombramiento del sucesor de Iturrigaray.

La plebe tampoco tuvo participación directa en la deposición del gobernante. Oportunamente fue informada de la prisión de Iturrigaray y del nombramiento de Pedro Garibay como su sucesor. Previendo una posible reacción popular, se comisionó a algunos clérigos para que estuvieran a mano en las calles al momento en que los habitantes de la ciudad leyeran la proclama.

Las fuerzas vivas del territorio, es decir, los miembros de las principales instituciones y agrupaciones, así como algunos prominentes personajes, fueron reunidas por el virrey buscando un consenso que apoyara sus determinaciones. Formaron una especie de consejo "notabiliario" que se reunió en varias ocasiones a discutir la situación. El consenso no fue logrado pues representaban múltiples intereses y posiciones.

Finalmente hay que señalar la participación de un elemento ajeno a la sociedad novohispana. Los representantes de la Junta Suprema que en Sevilla había asumido las atribuciones del poder real, traían la consigna de conseguir que la Nueva España reconociera dicha Junta y de reunir fondos para sostener la lucha contra Napoleón. Igualmente se sentían autorizados para deponer a Iturrigaray si éste no les proporcionaba su apoyo.

Podemos concluir que entre los dos golpes de estado se nota la aparición y participación de ciertos grupos que emergieron paulatinamente y que llegaron a detentar un gran poder político. Lo que podría verse como una cierta disminución en el poder eclesiástico, en realidad corresponde a una neutralidad por no haber atentado contra su poder terrenal. En cambio, si se atiende el papel del ejército, podemos ver que su autoridad va evolucionando hacia lo que sabemos sucedió más adelante en el siglo XIX, en que se volvió sostén y fuerza de los grupos en el poder.

En la reacción y actuación de las instituciones y corporaciones en el desarrollo de los acontecimientos se puede ver una muestra del acomodo de fuerzas que se unen o separan en torno a determinado asunto y según convenga a sus intereses. En el caso de 1624, se puede percibir una pos- 
tura casi unánime contra el virrey por parte de la Audiencia, el Ayuntamiento, el clero y los comerciantes. En cambio en 1808, uno de los puntos más controvertidos fue precisamente el conflicto entre la Audiencia y el Ayuntamiento, que quedó prácticamente solo frente al resto de las instituciones.

\section{Los medios}

Ahora habría que preguntarse cuáles fueron las estrategias que siguieron los diversos actores para la consecución de sus objetivos.

En 1624, lo que comenzó como una serie de roces entre los ayudantes del arzobispo y del virrey, se salió de proporción y llevó a Pérez de la Serna a agregar el nombre del marqués de Gelves a su ya larga lista de excomulgados como un hecho sin precedentes. La primera reacción de Gelves fue buscar el apoyo de la Audiencia pero sólo obtuvo de ella una tibia respuesta. Su siguiente recurso fue reunir a un grupo de catedráticos universitarios, que emitió un dictamen a su favor negando la legitimidad del decreto arzobispal, sentencia que fue ratificada por el representante papal en Nueva España, el doctor Moreno, coadjutor de la diócesis de Puebla.

Las reacciones del arzobispo eran cada vez más radicales y ya no sólo atentaban directamente contra la persona del virrey. Amenazó con imponer la cessatio a divinis, es decir la suspensión de los oficios divinos en la iglesia, el recurso más temible y temerario a que podía acudir, y cuando se presentó ante la Audiencia, recibió como respuesta la sentencia de ser deportado a España. Las acciones del arzobispo no cesaron al momento de abandonar la ciudad de México ya que dejó instrucciones para ratificar la excomunión de Gelves y para poner en vigor la suspensión del culto.

La Audiencia, aparentemente obligada por Gelves a firmar la expulsión del arzobispo, se arrepintió de tal medida y declaró suspendida la sentencia. Enterado de esto, el virrey ordenó el arresto de los oidores. La tensión fue en aumento y llegó a su culminación el 15 de enero de 1624, cuando se proclamó la temida cessatio a divinis. La turba, manipulada y enardecida, arremetió contra la sede del gobierno virreinal y sus representantes.

El virrey esperaba probablemente que milicias y guarniciones acudieran en su ayuda pero no sucedió así. La Audiencia, considerando depuesto 
a Gelves, nombró capitán general y comandante de la milicia a Pedro Vergara Gabiria, quien puso bajo su mando cuatro mil hombres.$^{14}$ Esta fuerza militar no defendió el palacio sino que trató de impedir la entrada de mayor numero de "tumultuarios" en la plaza mayor. Como último recurso, Gelves ordenó a su guardia personal que disparara desde la azotea, lo cual, en vez de frenar a la turba, la enardeció más.

La estrategia seguida por Gelves para salvar su vida es bastante peculiar. Se sabe que en ocasiones recurría al uso de disfraces para salir a la calle a espiar a los oficiales reales y "descubrir los vicios de la república". ${ }^{15}$ Con esa experiencia en mente y cuando vio que el asedio al palacio podía terminar mal para su persona, se quitó las gafas, descosió las insignias de su capa, se puso en el sombrero un trapo blanco que era común entre sus perseguidores, se confundió con el gentío y se unió a las voces en su contra: "Viva la fe y muera el mal gobierno de este luterano". ${ }^{16}$ De este modo consiguió llegar al convento de San Francisco, donde se refugió.

Algo que es digno de consideración es el significado del ataque al palacio, ya que no sólo lleva implícito la apropiación de la sede del poder. En una sociedad tan afecta a los rituales simbólicos, cabe considerar qué tan conscientes de sus acciones estaban los amotinados descargando su furia contra los símbolos del gobierno de Gelves, sus muebles, sus papeles, etcétera. Y más que eso, cabría preguntarse si en caso de haber encontrado al virrey, habrían tenido la osadía de arremeter contra su real persona.

Gelves había querido hacer uso de los símbolos del poder real mandando que ondeara desde un balcón de palacio el estandarte del rey. Pero cual no sería su sorpresa al enterarse que alguien lo había desprendido para izarlo luego en la parte más alta de la catedral. ${ }^{17}$ Esto puede interpretarse en el sentido de que la turba ya no obedecía al virrey que representaba a la máxima autoridad y buscaba otro tipo de legalidad.

El arzobispo había tenido mayor éxito escudándose en los símbolos de ese poder divino. Durante su camino al exilio y ante la presencia de los oficiales que pretendían obligarle a apresurar su marcha, entró en un templo, se impuso el traje pontifical y, sosteniendo la custodia en una mano y

14 Israel, J.: Raza, clases sociales..., pág. 160.

15 Memorial hecho y firmado por 113 vascongados el 1 de noviembre de 1625, citado por R. Boyer:"Absolutism...", pág. 488.

16 Cavo, A.: Historia de México..., pág. 293. pág. 156.

17 Gutiérrez Flores-Lormendi: Relación sumaria, citada por Israel, J.: Raza, clases sociales..., 
el báculo arzobispal en la otra, desafió a los ministros del virrey a atropellar su persona. ${ }^{18}$

La Corona también recurriría al simbolismo cuando, meses más tarde, reinstaló a Gelves en la silla virreinal para que hiciera la entrega formal del poder a su sucesor, el marqués de Cerralvo.

En 1624, según se desprende de algunas de las relaciones citadas por Mora, se efectuó una conspiración en casa del presbítero Salazar pero "nadie habló de substraerse de la dominación española ni de la obediencia al monarca; las ideas de independencia no estaban a la altura de los conocimientos del clero, pero se querían cosas peores para el gobierno, pues se pretendía precisarlo a establecer en México una administración teocrática". ${ }^{19}$

Los sucesos de 1808 revelan otro tipo de tácticas empleadas por los distintos actores. Después de la inicial confusión creada por la llegada de noticias tan insólitas de España, el virrey tuvo que cumplir con las formalidades de hacer las demostraciones públicas conducentes. Poco a poco, fue llevando a cabo ciertas acciones de gobierno, vistas por sus opositores como una usurpación del poder real: publicó un indulto a nombre del rey, creo el cuerpo de Voluntarios de Fernando VII, intensificó la colecta de donativos para sostener la lucha contra los franceses, dictó instrucciones específicas para la defensa del reino, nombró mariscales de campo e incluso se rumoreó que preparaba su coronación.

Ante lo crítico de la situación, el Ayuntamiento determinó presentarse ante el virrey "bajo de mazas, con uniforme de gala" y rodeado del pueblo al que habían arrojado monedas, para leer una representación formada por el regidor Juan Francisco Azcárate. En ella se consideran insubsistentes las abdicaciones y se manifiesta que "por ausencia o impedimento de los legítimos herederos, reside la soberanía representada en todo el reino y las clases que lo forman". ${ }^{20}$ La llamativa ceremonia y esta explosiva declaración fueron los primeros elementos de presión que utilizó el Cabildo.

La Audiencia se escandalizó ante esa idea pero de inmediato se hizo evidente que existía una división interna, ya que uno de sus miembros, el alcalde de corte Jacobo de Villaurrutia, propuso como único medio de evitar los desastres que amenazaban, "reunir una junta representativa del reino, declarando al virrey la autoridad suprema en lo necesario". ${ }^{21} \mathrm{El}$

18 Gage, T.: Viajes..., pág. 76.

19 Mora, J.M.L.: México ...,, págs. 246-247.

20 Reproducida en Mier, fray S. Teresa de: Historia ..., T. I, pág. 5.

21 Alamán, L.: Historia ..., pág. 114. 
Ayuntamiento insistiría en esta idea y finalmente el virrey convocó una primera junta para el 9 de agosto de 1808, aún en contra de las protestas de la Audiencia. Ésta debió cambiar su estrategia para no perder su preeminencia en los asuntos novohispanos.

En esta primera junta de fuerzas se llegaría, aunque no muy fácilmente, a ciertos acuerdos generales: manifestar la fidelidad de Nueva España a los Borbones y el rechazo a Francia, velar por la seguridad de la patria y ratificar la legitimidad de las autoridades constituidas. ${ }^{22}$ La discusión continuaría encaminada a la convocatoria de un Congreso General del Reino y al reconocimiento de las Juntas de Gobierno establecidas en España, aumentando la duda sobre dónde residía la legitimidad.

Ante las medidas del virrey, o tal vez ante su vacilación, se fue organizando la resistencia en su contra. Los miembros de la Audiencia y los principales comerciantes escogieron como líder del movimiento y ejecutor de los acuerdos de la conspiración a Gabriel de Yermo, enemigo personal del virrey y muy respetado por el grupo español. Éste preparó un plan, que consistía en convencer o sobornar a la guardia de palacio, contar con la complicidad del Regimiento Urbano de Comercio encargado de la guarnición de la ciudad a fin de que no interviniera, y hacer que un grupo de trescientos comerciantes menores cumpliera las comisiones de entrar al palacio, tomar prisionero al virrey, la virreina, sus hijos y colaboradores y, en caso de éxito, dar aviso a los miembros de la Audiencia, arzobispo y notables. El virrey, efectivamente, fue arrestado en sus habitaciones prácticamente sin "ejecución de violencia".

En 1808 la Audiencia no estaba facultada para asumir funciones ejecutivas pero sí se abrogó la de nombrar como sucesor del virrey a Pedro Garibay. Con esta acción, se habían violado las leyes de la materia que obligaban a la apertura de los llamados Pliegos de Providencia, donde se expresaba el nombre del sucesor. ${ }^{23}$ Una vez más se hace evidente que se actúa no por obedecer una ley sino por cumplir con algunos intereses.

El golpe de 1808 no tuvo como fin el derrocar al gobierno español en su conjunto ni una idea separatista. Por el contrario, se trataba de evitar que

22 Estos puntos se dieron a conocer en una proclama publicada en la Gazeta extraordinaria del viernes 12 de agosto de 1808 , t. XV, n. ${ }^{\circ} 77$, págs. 560-562.

23 Seguramente se temió que el sucesor fuera otro favorito de Godoy. Aparentemente los escogidos eran Roque Abarca y el marqués de Someruelos. Lafuente Ferrari, E.: El virrey Iturrigaray ..., pág. 261. Se tiene conocimiento de que la Junta Suprema de España, establecida en Sevilla, había nombrado como sucesor de Iturrigaray a Gregorio de la Cuesta. AGI, Indiferente General, 1349, 30 de mayo de 1808 . 
el virrey pudiera, apoyado por el Cabildo y el ejército, declarar la independencia respecto a España y establecer un gobierno autónomo.

Aceptando la definición de Carl Friedrich de que la autoridad no es el poder sino más bien el fundamento del poder ${ }^{24} \mathrm{e}$ incluso entendiéndola como sinónimo de legitimidad, resulta interesante analizar si los conflictos fueron ataques directos al poder o a la legitimidad. En 1808 el argumento que utilizó el Ayuntamiento fue que, para darle legitimidad al poder, era necesario que la soberanía emanara del pueblo, entendido como las autoridades constituidas, y se depositara en su gobernante, llenando así el vacío entre el virrey y el monarca. En 1624 fue el propio Gelves quien mostró la mayor preocupación por el estado de la legitimidad y, al mismo tiempo que lamentaba el golpe a la real autoridad, se percató de lo difícil que sería restaurar el respeto perdido a la institución virreinal. En ambos casos el afectado ha sido, pues, el fundamento del poder real.

\section{Resultados}

Las consecuencias del derrocamiento de los virreyes fueron diversas. Hay que resaltar entre ellas las que sufrieron los autores del cambio. Florescano, al referirse al golpe de 1624, afirma que

"la exacta medida de la debilidad de la corona y de la enorme fuerza que habían adquirido los intereses locales en la Nueva España la expresa el hecho de que [...], en lugar de proceder a los ejemplares castigos esperados, tuvo que disimular [enviando un Comisionado del Consejo de Indias] para anunciar un perdón general, que fue recibido con júbilo por los criollos de la ciudad de México".25

Aparentemente ese enviado sería el arzobispo Manso y Zúñiga, que emitió un indulto general el 20 de enero de $1628 .{ }^{26}$ Sin embargo con anterioridad el marqués de Cerralvo, por orden del rey, declaraba:

"que además de que el alboroto fue causado por la plebe y de ella la gente más menuda y de menos capacidad y aun de estos la inquietud no se dirigió contra la corona sino contra el virrey; en consecuencia, para que en el dicho caso los que en él se halla-

24 Friedrich, Carl J.: Tradition and Authority, citado por Timothy E. Anna: La caída del gobierno español en la ciudad de Mexico, Mexico, 1981, pág. 14.

25 Florescano, E. y R. Martínez: Historia gráfica ..., pág. 62.

26 Israel, J.: Raza, clases sociales ..., pág. 178. 
ron no puedan padecer ni haber padecido deslealtad al rey, usando su natural benignidad, S. M. manda que todas las personas, de cualquier estado y calidad que sean, sobre este alboroto estuviesen presos o procesados, sean sueltos libremente sin que ahora ni nunca puedan ser castigados por las dichas causas". ${ }^{27}$

A pesar de dicho indulto, se han localizado diversos testimonios que indican la ejecución de una "cacería de brujas". El detonador del conflicto, Varaez, por lo que se ha podido averiguar, no recibió un castigo muy severo. Durante el motín, una parte de la turba fue a sacarlo del templo de Santo Domingo donde estaba preso, y lo llevó "en triunfo a la catedral". ${ }^{28}$ Bancroft, basándose en una relación del suceso, afirma que apareció por las calles con gran ostentación y procedió a someterse al juicio de residencia de su alcaldía mayor, acompañado de 50 hombres a caballo que sin duda intentaban intimidar a los testigos honestos que pudieran atreverse a declarar en su contra. ${ }^{29}$ Se ha dicho que junto con otras personas, llevó a cabo ciertas maniobras de agitación contra Martín Carrillo.

Este enviado de la Corona realizó una minuciosa investigación y llegó a juntar una lista de varios centenares de sospechosos contra los que se procedió jurídicamente, a pesar de la reticencia del virrey Cerralvo. En 1626 "causó sensación en todo México la noticia de que el propio Vergara Gabiria estaba detenido". ${ }^{30}$ Poco después, iría a España en el mismo barco que Carrillo y que Gelves. Por su parte, De la Serna hubo de mantenerse un tiempo en suspenso hasta recibir la silla, de menor graduación, de obispo de Zamora. Finalmente a Gelves se le sometió al juicio de residencia, del que salió con honor, y cuando regresó a España, había pasado suficiente tiempo para reducir el impacto de los sucesos en que había estado involucrado. ${ }^{31}$

Las reacciones ante el hecho consumado fueron tan diversas como se puede imaginar. En 1624, una vez conocida la proclama expedida por la Audiencia, se hizo sentir un beneplácito en prácticamente todos los sectores; incluso se popularizó el verso

"Ahora vivamos en nuestra ley que ya no hay virrey".

27 Citado en Feijoo, R.: "El tumulto ...", pág. 67.

28 Ibídem, pág. 55.

29 Bancroft, H. H.: History of México ..., pág.75.

30 Israel, J.: Raza, clases sociales ..., pág. 175.

31 Bancroft, H.H.: History of Mexico ..., pág. 77. 
En cuanto a reacciones fuera de la ciudad de México, se tiene evidencia de alguna oposición por parte del gobernador del Puerto de Acapulco, con el apoyo de Tixtla e Iguala, pero que no llegó a nada, y de las críticas de un grupo de vascos en Puebla que no vieron con buenos ojos la deposición, sin haberse encontrado otros testimonios sobre más reacciones. Con el paso del tiempo y ante la política seguida por el gobierno interino de la Audiencia, el populacho, que unos meses antes había gritado "mueras" al virrey, comprendió que su gobierno no había sido tan malo y al momento en que Gelves fue reinstalado en la silla virreinal y aún cuando salió hacia España, lo aclamó vivamente, evidenciando que lo había "perdonado".La reacción más importante fue la de la corte española, que quedó atónita. En un primer momento no supo a quién culpar por el desafío a su autoridad y luego empezó a demostrar una gran desconfianza hacia la Audiencia, a la que le quitó la facultad de asumir el poder ejecutivo nombrando sustitutos o prelados provisionales en caso de faltar el virrey.

Los actores del conflicto de 1808 tuvieron distintos destinos. Aquellos considerados independentistas o cómplices de Iturrigaray fueron hechos prisioneros junto con él: su secretario de cartas Rafael Ortega, los licenciados Francisco Primo de Verdad y Ramos, Juan Francisco Azcárate y José Antonio del Cristo, el fraile mercedario Melchor de Talamantes, el canónigo José Mariano Beristáin y el abad de Guadalupe Francisco Beye Cisneros. ${ }^{32}$

Algunos de los golpistas pidieron una recompensa para Yermo y, aunque en principio no lo rechazó, el virrey Venegas traía para él un título nobiliario que tampoco aceptó. Los comerciantes consiguieron controlar durante algún tiempo a los virreyes sucesores de Iturrigaray pero mantuvieron el resentimiento de no haber sido reconocidos plenamente como los conservadores de la paz y la unión a España. El arzobispo Lizana y Beaumont llegaría a ocupar la silla virreinal pero siempre temeroso de ser el siguiente gobernante depuesto.

Las reacciones en 1808 también son interesantes. Una vez conocida la proclama de destitución de Iturrigaray, circuló un pasquín que decía:

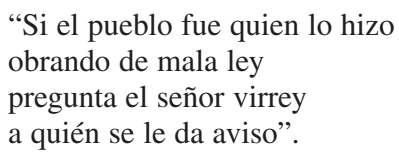

32 Lafuente Ferrari, E.: El virrey Iturrigaray ..., pág. 253. 
En este caso sí se tienen testimonios de diversas reacciones, todas favorables al golpe, por parte de la Diputación Minera de Guanajuato, el Cabildo Eclesiástico de Valladolid de Michoacán y los Ayuntamientos de Veracruz, Guadalajara y Zacatecas. La actitud de las autoridades españolas fue diversa, dependiendo de quién se encontrara asumiendo la soberanía.

El conflicto de 1624, que terminó con un aparente triunfo del arzobispo, fue como dice Israel, "una revolución porque por primera vez en la historia de las Indias un virrey había sido derrocado y mediante su caída se suspendió y destruyó todo un programa reformista que originalmente había sido iniciado en Madrid". ${ }^{33}$ En 1808 se instaló un gobierno ilegítimo que envió prisionero a España al representante del rey. En ese año, los criollos perdieron la batalla pero no la guerra.

33 Israel, J.: Raza, clases sociales ..., pág.. 163. 